Ciência e Natura, Santa Maria, v. 37 n. 4 set-dez. 2015, p. 392-404

Revista do Centro de Ciências Naturais e Exatas - UFSM

ISSN impressa: 0100-8307 ISSN on-line: 2179-460X

\title{
ciênciaenatura
}

\section{ALTERAÇÃO NA COBERTURA VEGETAL E USO DA TERRA DA BACIA HIDROGRÁFICA DO ALTO RIO TOCANTINS (GOIÁS): INFLUÊNCIA DAS CARACTERÍSTICAS FÍSICAS E A RELAÇÃO COM AS COMUNIDADES INDÍGENAS}

\author{
Land use and land cover change of high Tocantins river basin (Goias, Brazil): influence of physical \\ characteristics and the relation with the indigenous communities
}

\author{
Patrick Thomaz de Aquino Martins ${ }^{1}$, Renata Mariana Póvoa Matos², Alines Francisca Bueno², \\ Alessandra Carla de Almeida Silva Sene Paixão ${ }^{2}$ \\ ${ }^{1}$ Universidade Estadual de Goiás, Câmpus Formosa, GO, Brasil. \\ ${ }^{2}$ Universidade Estadual de Goiás, Câmpus Minaçu, GO, Brasil
}

\section{RESUMO}

O objetivo do presente estudo é analisar a cobertura vegetal e uso da terra na bacia hidrográfica do alto rio Tocantins, estado de Goiás, com base nas alterações espaciais ocorridas no intervalo de 29 anos, na influência dos aspectos físicos nesta dinâmica e nos impactos desta nas comunidades indígenas. A metodologia foi fundamentada em técnicas de geoprocessamento e pesquisa bibliográfica. O recorte espacial foi definido a partir do processamento de modelos digitais de elevação (MDE), tomando como referência a rede de drenagem confluente à usina hidrelétrica (UHE) de Serra da Mesa, norte do estado de Goiás. Foram utilizadas imagens do satélite Landsat 5 e 8, as quais foram pré-processadas, realçadas e classificadas. A caracterização do meio físico foi realizada a partir da compilação de mapas temáticos (unidades geológicas, unidades geomorfológicas e solos) e do MDE. Para associação com a comunidade indígena, foi realizada pesquisa bibliográfica, buscando, na literatura, publicações vinculadas à história recente dos Territórios Indígenas presentes na área estudada. A classificação resultou em um mapa de uso e cobertura da terra composto por três classes: cerrado, cobertura antrópica e corpos d'água. Nos últimos 29 anos houve mudança na classe predominante, passando de cerrado para cobertura antrópica. Estas alterações ocupam, principalmente, áreas de Latossolos, em relevos planos, da superfície regional de aplainamento. No mesmo período, o cenário de transformação de paisagens atingiu duas comunidades indígenas: a do Avá-Canoeiro, com o surgimento da UHE, e a do Tapuia, por pressão fundiária. Esta configuração espacial direciona à conservação dos remanescentes de cerrado presentes na área estudada.

Palavras-chave: geoprocessamento, paisagem, dinâmica espacial

\begin{abstract}
The aim of this study is to analyze the land use and land cover in the upper Tocantins river basin, Goias state, based on the spatial changes in the range of 29 years, the influence of the physical aspects of its dynamic and its impacts on indigenous communities. The methodology was based on GIS techniques and literature. The spatial area was defined from the processing of digital elevation models (DEM), in reference to the drainage basin confluent to "Serra da Mesa" hydroelectric plant (HEP), northern state of Goiás . Landsat 5 and 8 satelite images were used, which were preprocessed, classified and highlighted. The characterization of the physical environment was carried from the compilation of thematic maps (geological units, geomorphic units and soils) and the MDE. To associate the indigenous community, literature search was performed, searching the literature, publications related to the recent history of Indigenous Territories in the area. The classification resulted in a land cover and land use map with three classes: Cerrado, Anthropogenic cover and Water bodies. Over the past 29 years there was a change in predominant class, from cerrado to anthropogenic cover. This alterations occupy, mainly, areas of Oxisols in flat reliefs, in regional planation surface. In the same period, the scenario of landscapes transformation hit two indigenous communities: the Avá - Canoeiro, with the emergence of HEP, and the Tapuia by land pressure. This spatial configuration directs the conservation of Cerrado remaining (fragments) present in the study area.
\end{abstract}

Keywords: geomatic, landscape, spatial dinamic 


\section{INTRODUÇÃO}

A bacia do rio Tocantins compreende uma das principais regiões hidrográficas brasileiras. No norte do estado de Goiás, especificamente no trecho estadual correspondente ao alto rio Tocantins, foram instaladas duas usinas hidroelétricas (UHEs), a de Serra da Mesa e a de Cana Brava, as quais influenciam diretamente na configuração da paisagem regional.

Sendo, possivelmente, as alterações antrópicas mais flagrantes no nortenordeste goiano, as UHEs estão inseridas em uma região caracterizada por possuir, de acordo com Sano et al. (2008), as mais extensas áreas de cerrado ainda preservadas do estado. Entretanto, por estar localizado mais a montante, sendo exutório artificial de toda área de cabeceira, a qual atinge o centro do estado e parte do Distrito Federal, a bacia de drenagem confluente à UHE de Serra da Mesa já está tendo parte de sua área transformada em coberturas antrópicas.

Diferentemente da região Centro-Sul do estado, onde aproximadamente 63\% da vegetação natural já foi substituída por coberturas antrópicas, notadamente agricultura ou pastagem (SANO et al., 2008), os aspectos físicos, como as formas de relevo e tipos de solo, parecem ser limitantes à reprodução do padrão de expansão da fronteira agrícola vigente nas demais regiões do estado.

O histórico recente de modificações antrópicas da paisagem, bem como o avanço destas modificações no norte de Goiás, legitima a busca pelo conhecimento das alterações espacialmente explícitas. Com uma abordagem integrada, sob a perspectiva geográfica, esta meta torna-se possível e pode contribuir ao estabelecimento de áreas à conservação do Cerrado goiano.

Neste contexto, o presente estudo tem como objetivo entender a dinâmica espaço-temporal da cobertura vegetal e uso da terra da bacia hidrográfica do alto rio Tocantins, identificando a contribuição dos elementos físicos, bem como a interação com uma categoria de comunidade tradicional (indígena) na configuração do mosaico paisagístico.

\section{METODOLOGIA}

\section{BANCO DE DADOS GEORREFERENCIADO}

Os dados utilizados no presente estudo foram organizados e processados em um Sistema de Informações Geográficas, utilizando os aplicativos ArcGIS, Quantum GIS e SPRING (CÂMARA et al., 1996). Adotou-se o sistema de coordenadas geográficas e Datum World Geodetic System 1984 (WGS-84, EPSG: 4326), sendo reprojetado todo dado que não estivesse neste sistema de referência.

\section{ÁREA DE ESTUDO}

O recorte espacial foi definido a partir do processamento de Modelos Digitais de Elevação (MDE), obtidos junto ao Banco de Dados Geomorfométricos do Brasil (TOPODATA, 2014), tomando como referência a rede de drenagem confluente à 
represa de serra da mesa $\left(13^{\circ} 50^{\prime} 00^{\prime \prime} \mathrm{S}, 48^{\circ} 18^{\prime} 18^{\prime \prime} \mathrm{O}\right)$, alto rio Tocantins, norte do estado de Goiás.

Foram utilizadas, à delimitação, nove cenas de MDE: 13S495ZN, 14S48_ZN, 14S495ZN, 14S51_ZN, 15S48_ZN, 15S495ZN, 15S51_ZN, 16S495ZN e 16S51_ZN. O processamento compreendeu, respectivamente, as seguintes etapas: preenchimento dos sinks, direção de fluxo, fluxo acumulado e delimitação da rede de drenagem, de acordo com o proposto por Alves Sobrinho et al. (2010).

\section{MAPEAMENTO DO USO E COBERTURA DA TERRA}

A partir dos catálogos de imagens do INPE (DGI/INPE, 2014) e do EarthExplorer (USGS, 2014), foram obtidas, respectivamente, imagens do satélite Landsat 5, sensor TM, e Landsat 8, sensor OLI. Os detalhes destas imagens podem ser observados no Quadro 1.

Quadro 1 - Detalhes das imagens utilizadas no presente estudo.

\begin{tabular}{|c|c|c|c|c|c|}
\hline Catálogo & Satélite & Sensor & Órbita/Ponto & $\begin{array}{c}\text { Resolução } \\
\text { espacial }\end{array}$ & $\begin{array}{c}\text { Data do } \\
\text { imageamento }\end{array}$ \\
\hline \multirow{5}{*}{ INPE } & \multirow{5}{*}{ Landsat 5} & \multirow{5}{*}{$\mathrm{TM}$} & $221 / 070$ & \multirow{10}{*}{$30 \mathrm{~m}$} & $11 / 06 / 1984$ \\
\hline & & & $221 / 071$ & & $11 / 06 / 1984$ \\
\hline & & & $222 / 069$ & & 05/08/1984 \\
\hline & & & $222 / 070$ & & 05/08/1984 \\
\hline & & & $222 / 071$ & & 05/08/1984 \\
\hline \multirow{5}{*}{ USGS } & \multirow{5}{*}{ Landsat 8} & \multirow{5}{*}{ OLI } & $221 / 070$ & & $29 / 07 / 2013$ \\
\hline & & & $221 / 071$ & & $29 / 07 / 2013$ \\
\hline & & & $222 / 069$ & & $05 / 08 / 2013$ \\
\hline & & & $222 / 070$ & & $05 / 08 / 2013$ \\
\hline & & & $222 / 071$ & & 05/08/2013 \\
\hline
\end{tabular}

As imagens foram pré-processadas e realçadas, de acordo com as seguintes etapas: transformação radiométrica às imagens OLI, de 16 para 8bits; composição colorida, R5G6B4, para as imagens OLI, e R4G5B4, para as TM; registro das imagens $\mathrm{TM}$, tomando como referência as imagens OLI, de onde foram obtidos 20 pontos de controle, com adoção de erro médio quadrático menor que 0.5 para cada ponto; recorte; aplicação de contraste linear; mosaico; e segmentação, com valores de 10 para similaridade e 40 para a área.

Após a segmentação, procedeu-se a classificação supervisionada das imagens, com o algoritmo Bhattacharya e limiar de aceitação de 99.9\%.

\section{CARACTERIZAÇÃO DO MEIO FÍSICO}

A caracterização do meio físico foi realizada a partir da aquisição de mapas temáticos do estado de Goiás, em formato vetorial, procedentes do Sistema Estadual de Geoinformação (SIEG, 2014). Foram obtidos o mapa de unidades geológicas (MOREIRA et al., 2008), o de unidades geomorfológicas (LATRUBESSE; CARVALHO, 2006) e o de solos (GOIÁS, 2005), o quais foram recortados, utilizando a bacia de drenagem delimitada. 
O MDE, utilizado à delimitação da bacia, foi empregado, ainda, à complementação da caracterização do meio físico, a partir da transformação em classes de declividade e altimetria (hipsometria).

\section{COMUNIDADES TRADICIONAIS}

Após o mapeamento da cobertura da terra nos dois períodos, foi realizada uma pesquisa bibliográfica, com a finalidade de identificar os territórios ocupados pelas comunidades tradicionais presentes na área de estudo e relacionar estas à dinâmica espacial do mosaico paisagístico.

\section{RESULTADOS E DISCUSSÃO DINÂMICA ESPAÇO-TEMPORAL DA COBERTURA VEGETAL E USO DA TERRA}

Os elementos que compõem a paisagem da bacia foram mapeados com a adoção de três classes, a saber: cerrado, caracterizado pelas três formações vegetais que compõe o bioma (floresta, savana e campo); cobertura antrópica, representada pelas áreas urbanas, mineração, pastagem implantada, agricultura, silvicultura, solo exposto e queimadas; e corpos d'água, demarcados pelos rios e lagos/represas. Alguns exemplos destes elementos podem ser observados na Figura 1.

A delimitação da área de estudo, bem como o padrão espacial e a dinâmica das classes mapeados podem ser observados na Figura 2. Com base na análise visual, ao comparar ambos os anos, é possível notar duas marcantes mudanças na paisagem: (1) o aumento da classe de uso antrópico; e (2) o surgimento de uma represa ao norte da área de estudo, referência de exutório para o presente trabalho. Tal constatação pode ser ratificada ao se examinar a Figura 3.

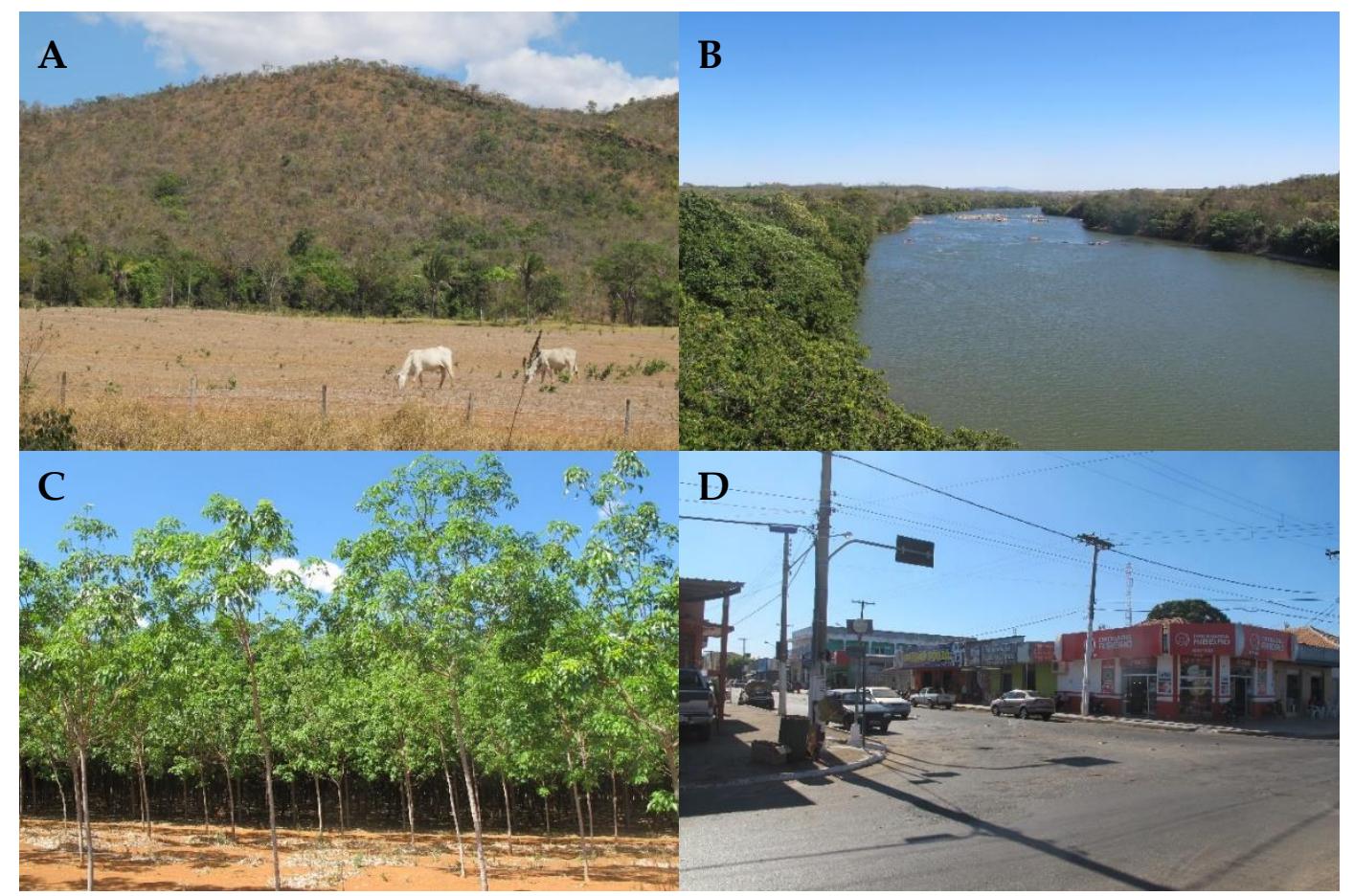


Figura 1 - Exemplos de elementos que compõem a paisagem. A - em primeiro plano, área de cultivo agrícola, associado a criação bovina, em segundo plano, no morro, savana (cerrado); B - Corpo d'água, ao centro, e vegetação ripária (cerrado), na borda; C - silvicultura; D - área urbana.

Em termos quantitativos, tem-se que, no ano de 1984, primeiro ano mapeado, a classe preponderante na bacia era composta pelas formações do cerrado, as quais ocupavam uma área de aproximadamente 3.363 .890 ha, i.e. $63 \%$ do total (Figura 3). As classes menos presentes neste ano cobriam cerca de 1.975 .718 ha, o que correspondia a mais de $36 \%$ de cobertura antrópica e $0,2 \%$ de corpos d'água.

Ao acompanhar as informações geradas para o ano de 2013, nas Figuras 2 e 3, constata-se que o cerrado deixou de ser a cobertura característica na bacia, pois passou a ocupar 47,9\% da área mapeada, enquanto que a cobertura antrópica passou a ter $49,8 \%$ e os corpos d'água $2,3 \%$. É possível notar, ainda, que a alteração na paisagem se deu de sul para norte e de oeste para leste, com sendo que a porção leste possui maiores áreas de remanescentes de cobertura natural.

A mudança no padrão da paisagem, e a modificação da classe preponderante, ocasionou o aumento da fragmentação da cobertura natural. $\mathrm{O}$ aumento da fragmentação resulta na diminuição da área, o que compromete a heterogeneidade e recursos, leva ao aumento da extinção, diminui a conectividade, os corredores, aumenta os tipos de borda, dentre outros, tendo como resultante a diminuição da biodiversidade (METZGER, 1999).
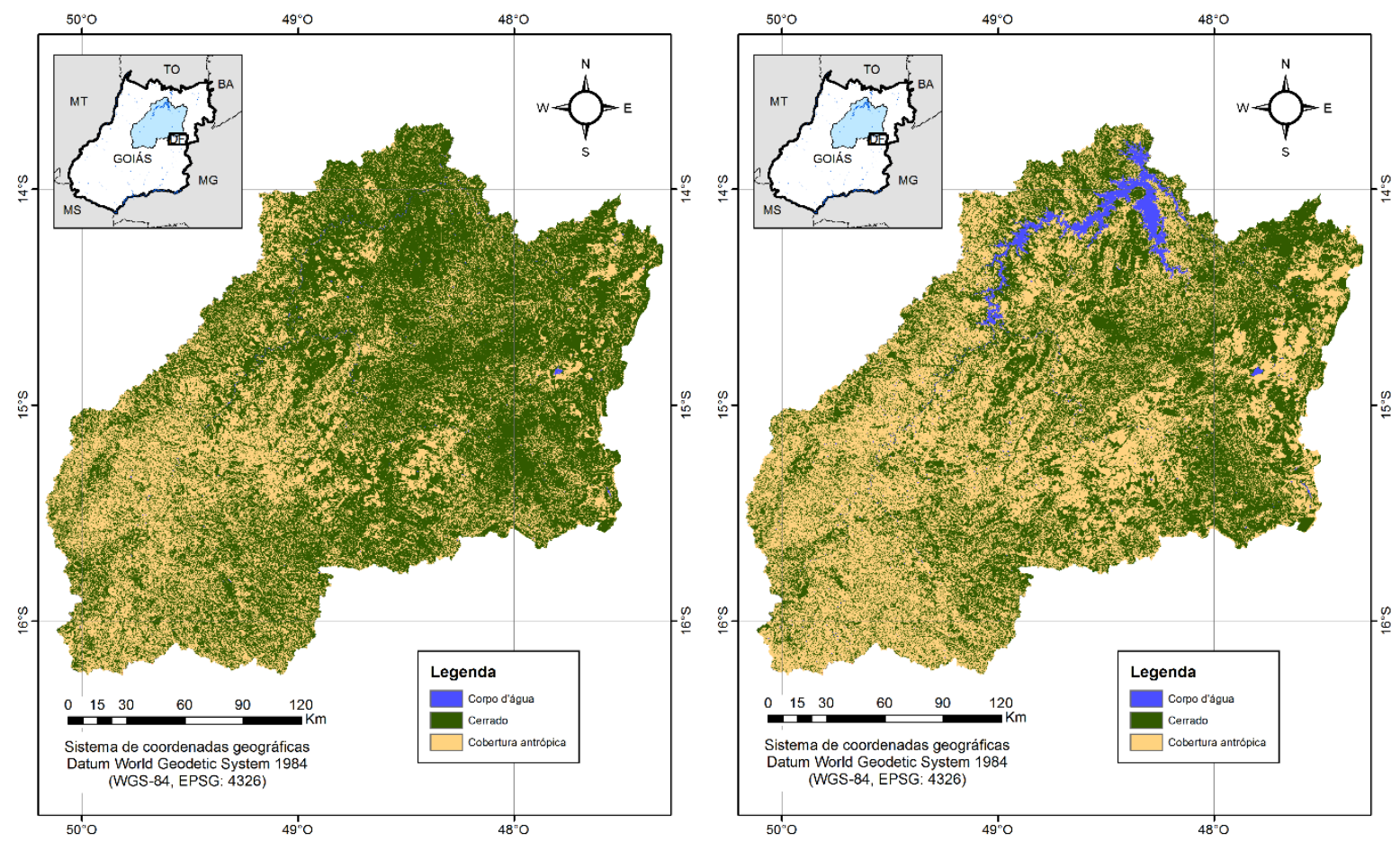

Figura 2 - Mapa de cobertura vegetal e uso antrópico da Bacia do alto Rio Tocantins, para os anos de 1984 (esquerda) e 2013 (direita). 
A dinâmica de substituição de remanescentes de cerrado pela cobertura antrópica pode ser explicada, majoritariamente, a partir da implementação do 'hidronegócio', responsável pela implementação da usina e lago de Serra da Mesa, no norte da bacia, o que corresponde ao aumento de $1000 \%$ na área ocupada pela classe corpo d'água; e pela expansão das atividades agropecuárias, setor responsável pela alteração do cerrado como um todo, como identificado por Rocha et al. (2011) e Ferreira Júnior et al. (2009).

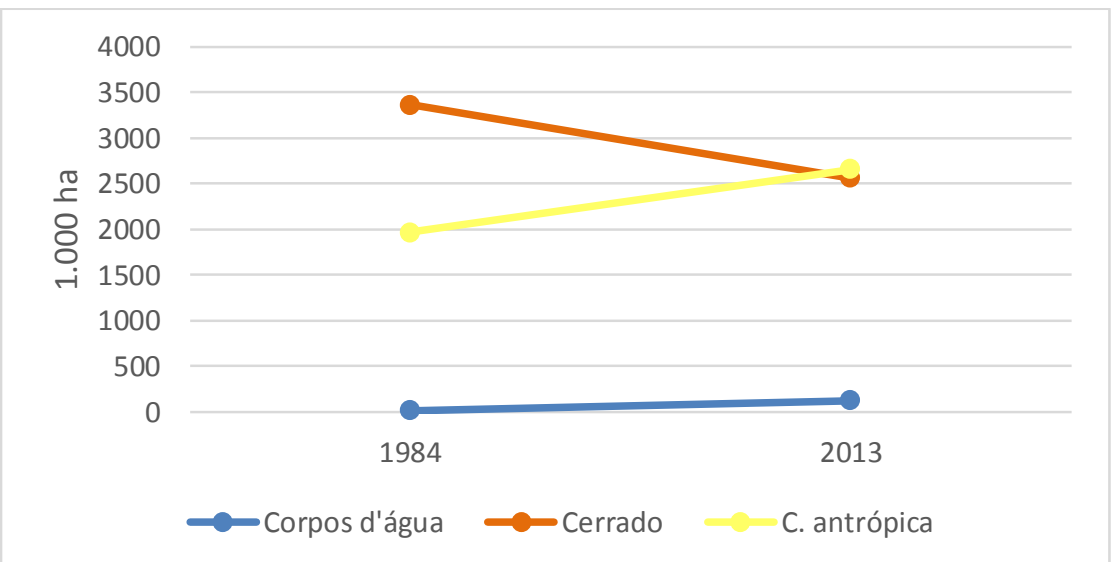

Figura 3 - Variação do quantitativo da cobertura da terra, para os anos de 1984 e 2013.

\section{CARACTERIZAÇÃO DO MEIO FÍSICO}

A configuração do meio físico, principalmente nos aspectos geomorfológicos e de solos, parece ter sido decisiva à conformação da cobertura antrópica na bacia. Ao observar o mapa de declividade (Figura 4), percebe-se a confluência entre as coberturas antrópicas e as áreas de relevo plano $(<3 \%)$, assim como a sua Unidade Geomorfológica correspondente, a Superfície Regional de Aplainamento (SRA).
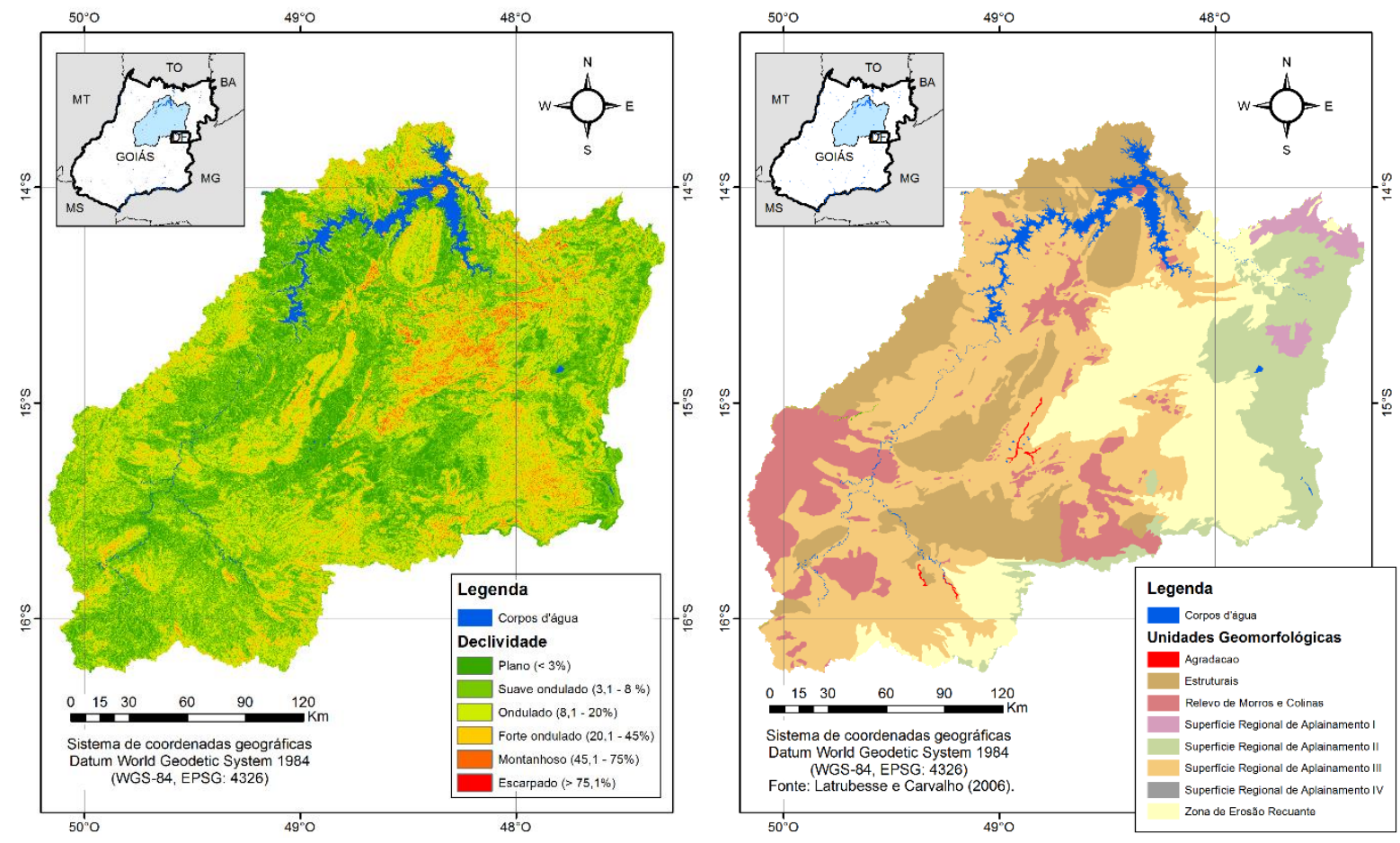
Figura 4 - Mapas de declividade (esquerda) e de Unidades Geomorfológicas (direita).

Uma das características das SRA é que estas não necessariamente respeitam limites litológicos ou estilos estruturais (LATRUBESSE; CARVALHO, 2006), perpassando várias Unidades Geológicas. No caso específico da área de estudo, por estar constituída por mais de 50 Unidades (Figura 5), a principal alteração antrópica associada a estas Unidades diz respeito à presença de minerais de importância econômica, como na estrutura pseudo dômica, no Complexo máfico-ultramáfico Niquelândia, ao norte, onde está localizada uma mina de cobre, e no Complexo máfico-ultramáfico Barro Alto, na faixa central da bacia, onde há uma mina de níquel.

A SRA possui 4 classes na área de estudo, as quais estão associadas a diferentes altitudes (LATRUBESSE; CARVALHO, 2006). Na SRA II, setor leste da bacia, são encontradas as maiores altitudes, com pouco mais de $1.660 \mathrm{~m}$, ao passo que na SRA III, mais à jusante, estão presentes as menores altitudes, com aproximadamente $404 \mathrm{~m}$ (Figura 6). Esta unidade geomorfológica guarda relação espacial com os Latossolos, o quais são associados às superfícies planas e, juntamente com os Cambissolos e os Neossolos, são os solos predominantes na área estudada (Figura 6).
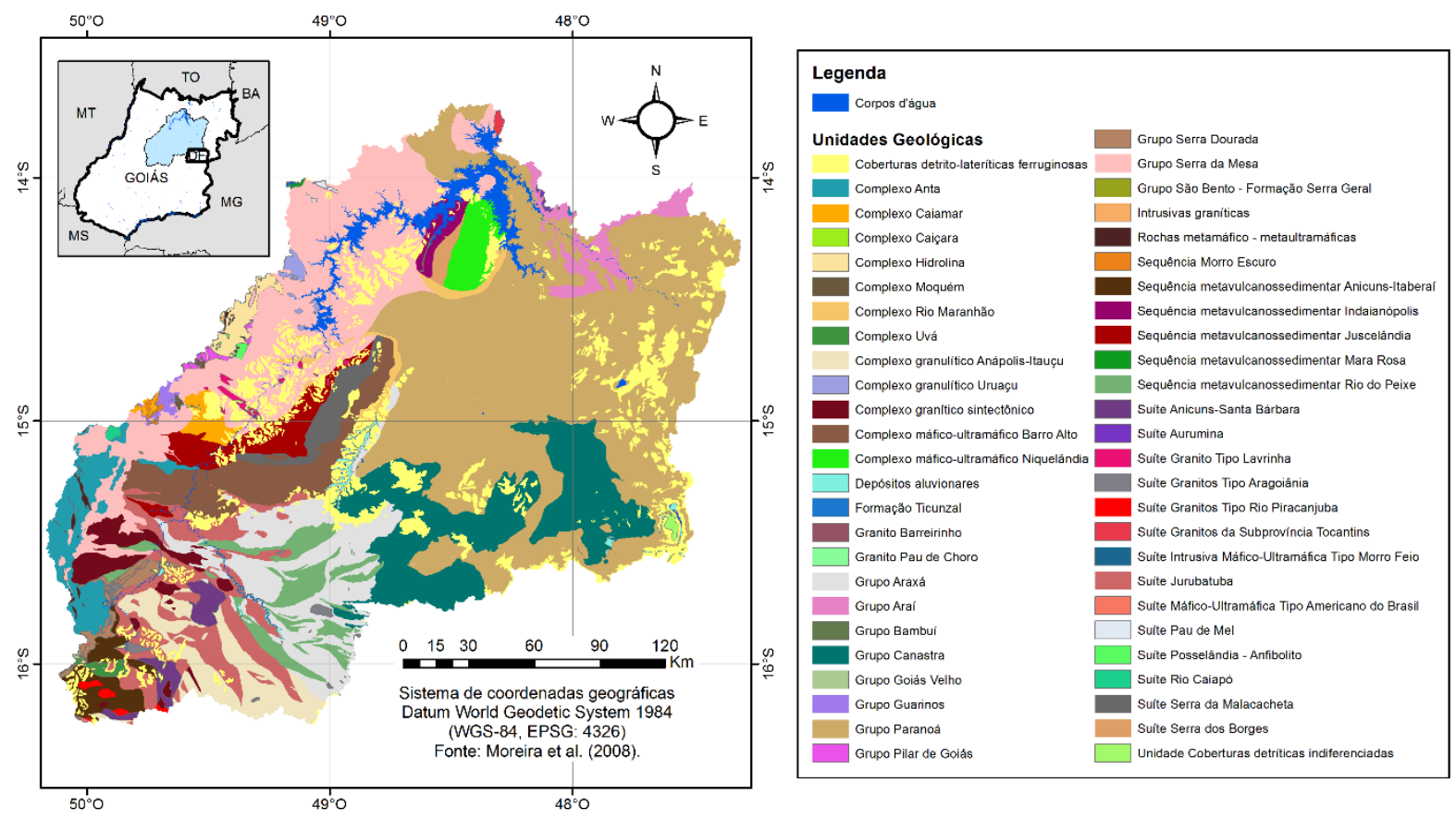

Figura 5 - Mapa geológico da bacia hidrográfica do alto Tocantins.

Embora compartilhem a hegemonia espacial, estes solos são distintos no tocante à potencialidade de uso agrícola. Enquanto o Cambissolo e o Neossolo são solos pouco desenvolvidos/evoluídos, o Latossolo é um solo em estágio avançado de intemperização, sendo normalmente profundo (EMBRAPA, 2006). 

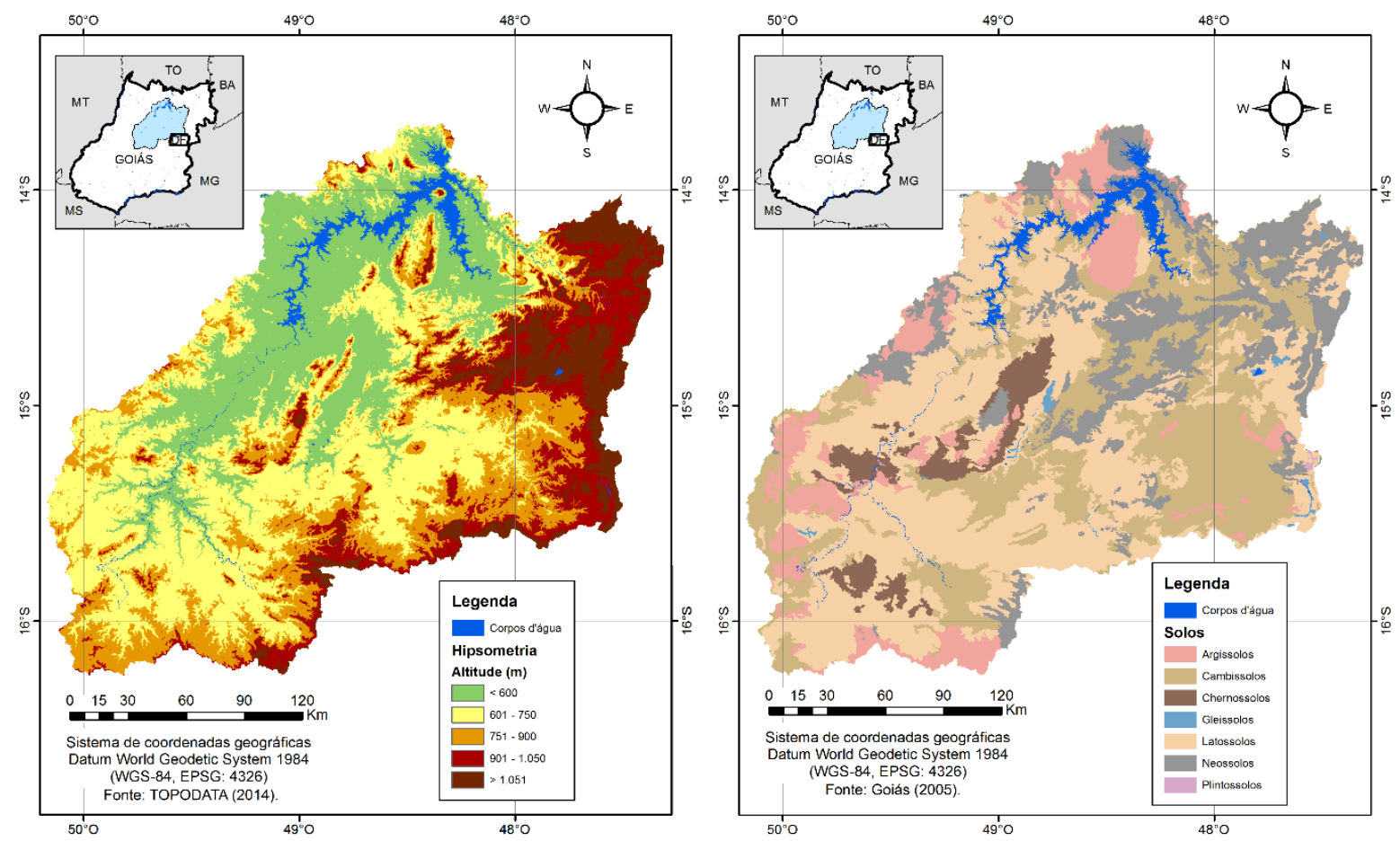

Figura 6 - Mapa hipsométrico (esquerda) e Mapa de Solos (direita) da área de estudo.

Assim, as áreas de remanescentes de cerrado ocupam áreas mais declivosas, as quais agregam de morros a escarpas e estão correlacionadas às Unidades Zona de Erosão Recuante, e solos inapropriados ao cultivo agrícola.

Apesar de ocupar áreas de menor declives (ROCHA et al., 2011), a substituição da vegetação de cerrado pela cobertura antrópica pode resultar no aumento de erosão (MACHADO; TORRES, 2012). Os sedimentos, produtos da erosão, poderão ser transportados aos rios e ocasionarem o assoreamento dos corpos d'água, o que resultaria na diminuição do potencial hídrico à geração de energia, e a disponibilidade hídrica à agricultura e ao consumo humano.

\section{A DINÂMICA DA PAISAGEM E AS COMUNIDADES INDÍGENAS}

A mudança na cobertura vegetal e uso da terra está relacionado, ainda, a questões territoriais de comunidades indígenas. Duas comunidades foram diretamente atingidas devido ao processo de ${ }^{c}$ udança da paisagem: a do AváCanoeiro e a do Tapuia (Figura 7). 


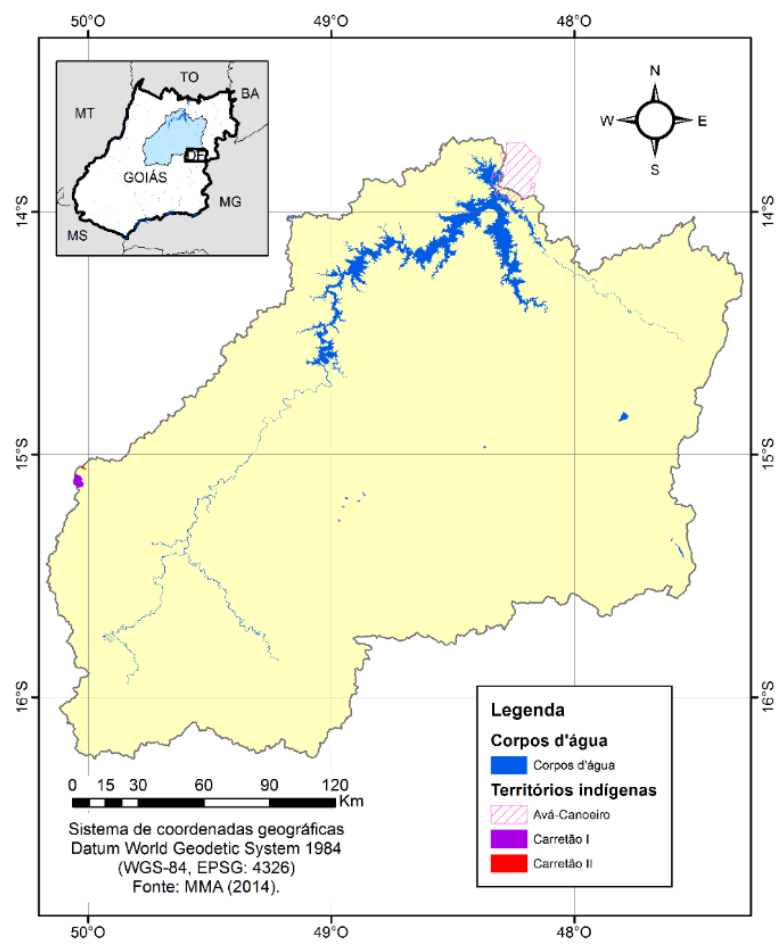

Figura 7 - Localização dos Territórios Indígenas presentes na bacia hidrográfica do alto rio Tocantins

A Terra Indígena Avá-Canoeiro foi acometida, principalmente, pelo aumento dos corpos d'água, devido ao surgimento da represa da UHE de Serra da Mesa e, de acordo com Silva (2010), tem sido elemento de disputa e conflito, permeado por atores e interesses de várias ordens, sendo os principais a UHE de Serra da Mesa e a Fundação Nacional do Índio (FUNAI), órgão responsável pela administração dos direitos dos índios. Além de sagrada, a terra é, para grande parte dos povos indígenas, onde viveram seus ancestrais e lugar onde habitam suas tradições (SILVA, 2010).

Koifman (2001) inventariou os impactos da geração e transmissão de energia elétrica no Brasil que incidem nas populações indígenas, levantamento que incluiu os Avá-Canoeiro. De acordo com este autor, além da submersão de territórios sagrados, as principais reclamações das comunidades indígenas no Brasil são a proliferação de mosquitos vetores de doenças, a escassez da caça, a restrição de terras à agricultura e a facilitação à invasão de terras indígenas.

Embora haja, na literatura, problemas relacionados à implantação da hidrelétrica, ou mesmo às atividades minero-extrativistas, o que é configurado como um tipo de pressão à comunidade dos Avá-Canoeiro, existem também benefícios resultante dessa modificação da paisagem da Terra Indígena, como, por exemplo, o Programa Avá-Canoeiro do Tocantins (PACTO).

De acordo com FURNAS (2014), o PACTO tem como objetivo ser uma compensação ao grupo indígena às interferências geradas pela 'implantação da Usina Hidrelétrica de Serra da Mesa, composto por subprogramas nas áreas de 
saúde, educação, meio ambiente, documentação, demografia e infraestrutura (Quadro 2).

Embora as ações de FURNAS e da FUNAI sejam laudáveis, algumas ações podem ser interpretadas como prejudiciais à comunidade em questão, como, por exemplo, a oferta de uma cesta básica mensal, o que, de acordo com Silva (2010), desestimula a pesca, a caça e a coleta.

Quadro 2 - Objetivos dos subprogramas do Programa Avá-Canoeiro do Tocantins.

\begin{tabular}{|l|l|}
\hline Subprograma & Objetivos \\
\hline Saúde & Garantir a higidez física dos Avá-Canoeiro \\
\hline Educação & $\begin{array}{l}\text { Resguardar a língua materna por meio de ensino } \\
\text { bilíngue }\end{array}$ \\
\hline $\begin{array}{l}\text { Meio Ambiente Proteção e Fiscalização da } \\
\text { Terra Indígena Avá-Canoeiro }\end{array}$ & $\begin{array}{l}\text { Relhorar as Condições de subsistência dos índios } \\
\text { meio da reunião da documentação história, } \\
\text { audiovisual e cultura material. }\end{array}$ \\
\hline Documentação e memória & $\begin{array}{l}\text { Apresentar alternativas para a sobrevivência dos } \\
\text { índios }\end{array}$ \\
\hline $\begin{array}{l}\text { Unificação do Povo Avá-Canoeiro } \\
\text { Crescimento Populacional }\end{array}$ & $\begin{array}{l}\text { Manutenção da infraestrutura necessária à proteção } \\
\text { dos índios }\end{array}$ \\
\hline Obras e Equipamentos & \\
\hline
\end{tabular}

Fonte: FURNAS (2014).

Na área da bacia há, ainda, outra comunidade indígena, a dos Tapuias, a qual é dividida em dois territórios, denominados Território Indígena Carretão I e Carretão II (Figura 3). Esta, porém, mesmo com histórico de conflitos pela terra, embate este ocorridos tanto silenciosamente quanto com mais vivacidade, e por estar ilhada pela presença de 60 fazendas (CHAVEIRO et al., 2011), não possui documentação bibliográfica densa relacionada ao espaço de tempo aqui analisado.

O aumento da produção agrícola no estado e a presença das propriedades agrícolas representam, por si só, pressão do agronegócio. Neste sentido, Silva (2013) informa que em 1984, primeiro ano mapeado, a marcação das glebas da Terra Indígena Tapuia se deu "em meio de intensos conflitos com os fazendeiros da região". De acordo com esta autora, mesmo com a participação do povo Tapuia na demarcação das glebas, algumas importantes áreas ficaram de fora, como o cemitério, localizado na antiga sede do aldeamento.

As populações indígenas são parte das comunidades afetadas diretamente no processo de mudança ocorrida na bacia nos últimos 29 anos. Há de se frisar que, além desta comunidade, existem outras que também sofreram ou sofrem com esta dinâmica espacial (e.g. ribeirinhas).

\section{CONCLUSÕES}

A tipologia de cobertura da terra predominante na bacia hidrográfica do alto rio Tocantins mudou, nos últimos 29 anos, de vegetação natural, composta pelas 
formações fitofisionômicas do cerrado, para coberturas antrópicas, caracterizados por áreas relacionadas às atividades agropecuárias e urbanas.

Identificou-se que há uma sobreposição espacial entre os parâmetros físicos e as tipologias de cobertura da terra. Este panorama pode resultar em complicações de ordem ambiental, tais como o assoreamento dos rios, a perda de habitat e biodiversidade.

Esta configuração espacial direciona à conservação dos remanescentes de cerrado presentes na área estudada, uma vez que há um equilíbrio natural dos elementos que compõem a paisagem natural.

Um sistema de gestão à mitigação das implicações produtos das alterações ocorridas na paisagem se faz necessário à bacia. Sem este, e permanecendo o ritmo de mudança, a bacia tende a perecer nas esferas hídrica e ecológica.

A alteração da paisagem impactou comunidades indígenas, notadamente os Avá-Canoeiros e os Tapuias. Enquanto os Avá-Canoeiros foram atingidos pela construção da UH de Serra da Mesa, e os Tapuias foram marcados pela situação fundiária, a qual tem sido foco de históricos conflitos.

Para além do imbróglio ambiental resultante das alterações no tipo de cobertura do Cerrado, as comunidades tradicionais que ocupam este bioma também passam por transformações, principalmente de ordem cultural. Assim como as alterações de cunho ecológico podem romper a barreira da resiliência, mudanças no aspecto humano, sobretudo no âmbito indígena, certamente são um caminho sem volta.

\section{AGRADECIMENTOS}

À Universidade Estadual de Goiás, pela concessão de bolsa de incentivo à pesquisa (BIP) ao primeiro autor; à Fundação de Amparo à Pesquisa do Estado de Goiás FAPEG, pelo financiamento da pesquisa; ao Programa Institucional de Bolsas de Iniciação Científica do $\mathrm{CNPq}$ - PIBIC/CNPq, pela concessão da bolsa ao quarto autor; ao Programa de Bolsas de Iniciação Científica - PBIC-UEG, pela concessão da bolsa ao segundo e terceiro primeiro autores; à Coordenação de Aperfeiçoamento de Pessoal de Nivel Superior - CAPES, pelo apoio financeiro, por intermédio do Programa FAPEG 2036/2013.

\section{REFERÊNCIAS}

ALVES SOBRINHO, T.; OLIVEIRA, P. T. S.; RODRIGUES, D. B. B.; AYRES, F. M. Delimitação automática de bacias hidrográficas utilizando dados SRTM. Engenharia Agrícola (Impresso), v. 30, p. 46-57, 2010.

CÂMARA, G.; SOUZA, R. C. M.; FREITAS, U. M.; GARRIDO, J. SPRING: integrating remote sensing and GIS by object-oriented data modelling. Comput Graph, v. 20. p. 395 403, 1996. 
CHAVEIRO, E. F.; SILVA, L. G.; LIMA, S. C. O Cerrado na perspectiva dos povos indígenas de Goiás: a arte de vida do povo Tapuia do Caretão-GO. Ciência e Cultura. v. 63, n. 3, p.3941, 2011.

DGI/INPE. Divisão de Geração de Imagens/Instituto Nacional de Pesquisas Espaciais. Catálogo de Imagens. Disponível em <http://www.dgi.inpe.br/CDSR >. Acesso em 01 ago 2014.

EMBRAPA - Empresa Brasileira de Pesquisa Agropecuária. Sistema Brasileiro de Classificação de Solos. Brasília: Embrapa-SPI, Rio de Janeiro: Embrapa-Solos, 2006. 306 p.

FERREIRA JÚNIOR, L. G.; FERREIRA, M. E.; ROCHA, G. F.; NEMAYER, M.; FERREIRA, N. C. Dinâmica agrícola e desmatamentos em áreas de cerrado: uma análise a partir de dados censitários e imagens de resolução moderada. Revista Brasileira de Cartografia, v. 61, p. 117-127, 2009.

FURNAS. Comunidade indígenas. Disponível em $<$ http://www.furnas.com.br/frmMAAcoesComunidadesIndigenas.aspx>. Acesso em 01 ago 2014.

GOIÁS. Agência Ambiental de Goiás. Mapa de Solos - Projeto RadamBrasil. Base de dados: Determinação de áreas prioritárias para unidades de preservação: - Cons. imagem/WWF. 08/07/2005. Disponível em: <http://www.sieg.go.gov.br/> Acesso em 01 ago 2014.

KOIFMAN, S. Geração e transmissão da energia elétrica: impacto sobre os povos indígenas no Brasil. Cadernos de Saúde Pública (FIOCRUZ), Rio de Janeiro, v. 17, n.2, p. 413-423, 2001.

LATRUBESSE, E, M.; CARVALHO, T. M. Geomorfologia do Estado de Goiás e Distrito Federal. Escala 1:500.000. Goiânia: Secretaria de Indústria de Comércio. Superintendência de Geologia e Mineração, 2006.

MACHADO, P. J. O.; TORRES, F. T. P. Introdução à hidrogeografia. São Paulo: Cengage Learning, 2012.

METZGER, J. P. Estrutura da paisagem e fragmentação: análise bibliográfica. Anais da Academia Brasileira de Ciências, v. 71, n.3-I, p. 445-463, 1999.

MMA. Ministério do Meio Ambiente. Mapa interativo do MMA. Disponível em $<$ http://mapas.mma.gov.br/i3geo/mma/openlayers.htm?5ss2gipe4vrvt2vbmne27ls424>. Acesso em 01 ago 2014.

MOREIRA, M. L. O.; MORETON, L. C.; ARAÚJO, V. A.; LACERDA FILHO, J. V.; COSTA, H. F. (Orgs.) Geologia do Estado de Goiás e Distrito Federal. Escala 1:500.000. Goiânia: CPRM/SIC-FUNMINERAL, 2008. 
ROCHA, G. F.; FERREIRA JÚNIOR., L. G.; FERREIRA, N. C.; FERREIRA, M. E. Detecção de desmatamentos no bioma cerrado: entre 2002 e 2009: padrões, tendências e impactos.

Revista Brasileira de Cartografia, v. 63, p. 341-349, 2011.

SANO, E. E.; ROSA, R., BRITO, J. L. S.; FERREIRA, L. G. Mapeamento semidetalhado do uso da terra do Bioma Cerrado. Pesq. agropec. bras., Brasília, v.43, n.1, p.153-156, jan. 2008.

SIEG. Sistema Estadual de Geoinformação de Goiás. Disponível em:

$<$ http://www.sieg.go.gov.br/> Acesso em 01 ago 2014.

SILVA, G. L. Avá-Canoeiros: guardiões do Cerrado do norte goiano. Ateliê Geográfico, v.4 no 1, p.116-138 Goiânia- GO. 2010

TOPODATA. Banco de Dados Geomorfométricos do Brasil. Disponível em:

<http://www.dsr.inpe.br/topodata/index.php> Acesso em 01 ago 2014.

USGS. United States Geological Survey. EarthExplorer. Disponível em:

$<$ http://earthexplorer.usgs.gov/> Acesso em 01 ago 2014. 